\title{
Estrogen-mediated Protection of Experimental Autoimmune Encephalomyelitis: Lessons from the Dissection of Estrogen Receptor-signaling In vivo
}

\author{
Sophie Laffont ${ }^{1,2,3}$, Laure Garnier ${ }^{1,2,3}$, Karine Lélu ${ }^{4}$ Jean-Charles Guéry ${ }^{1,2,3}$
}

\begin{abstract}
A growing body of evidence from basic and clinical studies supports the therapeutic potential of estrogens in multiple sclerosis (MS), originating from the well-established reduction in relapse rates observed among women with MS during pregnancy. The biological effects of estrogens are mediated by estrogen receptors (ER $\alpha$ and $\mathrm{ER} \beta$ ). Estrogens or selective ER-agonists have been shown to exert potent neuroprotective or anti-inflammatory effects in experimental autoimmune encephalomyelitis (EAE), the mouse model of MS. A central question in EAE is to identify the cellular targets that express a functional ER isotype, and the mechanisms underlying the neuroprotective and anti-inflammatory effects of estrogens. Using pharmacological approaches targeting ER-specific functions, and

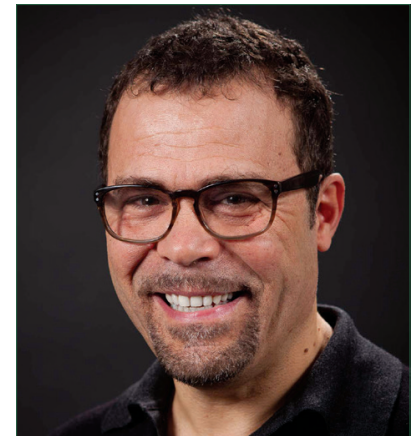

Dr. Jean-Charles Guéry genetic tools such as conditional knockout mice in which ER $\alpha$ or ER $\beta$ are selectively deleted in specific cell populations, a clearer picture is now emerging of the various cellular targets and downstream molecules responsible for estrogen-mediated protection against central nervous system autoimmunity. (Biomed J 2015;38:194-205)
\end{abstract} Key words: experimental autoimmune encephalomyelitis, estrogen, estrogen receptors,
immunoregulation, multiple sclerosis, neuroprotection

$\mathrm{M}$ ultiple sclerosis (MS) is a debilitating neurological autoimmune disease (AID) affecting 2.5 million people worldwide, with a female/male sex ratio of 3:1. MS and its mouse model, experimental autoimmune encephalomyelitis (EAE), are characterized by the infiltration of inflammatory leukocytes, including autoreactive T-cells, into the central nervous system (CNS), resulting in myelin damage. A large body of evidence from basic science and from preclinical and clinical studies points to anti-inflammatory and direct neuroprotective effects of estrogens in MS. ${ }^{[1]}$ The concept that estrogens may play a role in MS pathogenesis and disease activity, and, therefore, constitute potential for therapeutic agents, is based on the well-established clinical observation that women with MS constantly show a decrease in disease activity during pregnancy. ${ }^{[2]}$ This potent, short-term beneficial effect of pregnancy is not limited to women with MS, but also has been observed in other inflammatory AID, such as rheumatoid arthritis (RA) and psoriasis, followed by a temporary rebound of disease activity postpartum. ${ }^{[3,4]}$ Estrogens are the major candidate therapeutic agents in MS since they exert potent effects on the immune system and on the CNS, and peak during the last trimester of pregnancy, when the most pronounced decrease in the relapse rate occurs. Indeed, the therapeutic potential of estrogens, such as 17 $\beta$-estradiol (E2) or estriol (E3), has been clearly demonstrated in EAE. ${ }^{[4,5]}$ Moreover, in a pilot clinical trial of MS therapy, administration of estriol (E3) at doses related to pregnancy levels of the hormone was shown to exert beneficial effects. ${ }^{[6,7]}$ Large placebo-controlled clinical trials of estrogen therapy in MS are in progress. ${ }^{[4]}$

Although, clear evidence are emerging that E2 could inhibit CNS autoimmunity through distinct mechanisms,

From the ${ }^{1}$ INSERM, U1043, Toulouse, F-31300, France; ${ }^{2}$ CNRS, U5282, Toulouse, F-31300, France; ${ }^{3}$ Université de Toulouse, Université Paul Sabatier, Centre de Physiopathologie de Toulouse Purpan (CPTP), Toulouse, F-31300, France; ${ }^{4}$ Transgene S.A., 67405 Illkirch-Graffenstaden, France

Received: Nov. 6, 2014; Accepted: May 28, 2015

Correspondence to: Dr. Jean-Charles Guéry, INSERM UMR 1043, CHU Purpan, BP3028, 31024 Toulouse Cedex 3, France.

Tel: 33-5-62748378. FAX: 33-5-62744558. E-mail: Jean-Charles.Guery@inserm.fr

DOI: $10.4103 / 2319-4170.158509$ 
namely anti-inflammatory and neuroprotective actions, the cellular targets orchestrating these protective effects of E2 are only now being identified. Biological effects of estrogens are mediated through two nuclear estrogen receptors (ER) $\mathrm{ER} \alpha$ and $\mathrm{ER} \beta$, which are ubiquitously expressed in the body. We survey here the data from animal studies of the effects of exogenous or endogenous estrogens in EAE where genetic evidence exist of the direct implication of ER $\alpha$ and/or ER $\beta$. We highlight the recent development of tissue-specific conditional ER knockout strategies [Figure 1].

\section{The protective effects of pregnancy on central nervous system autoimmunity: A role for estrogens}

The female predominance in MS appears closely linked to the occurrence of puberty, suggesting that sex steroid hormones influence MS susceptibility. ${ }^{[8]}$ The female bias in MS could result either from the deleterious effect of female sex hormones or from the protective effect of male sex hormones. Although we have shown that low-dose estrogens promote inflammatory responses in vivo, ${ }^{[9-13]}$ evidence are lacking so far for a disease-promoting effect of estrogens in EAE. Reduced disease activity in MS patients is commonly observed during pregnancy, indicating that pregnancy-as- sociated hormones can confer transient protection to CNS autoimmunity. ${ }^{[2]}$ Pregnancy is characterized by an array of biological changes that could mediate both immunomodulatory and neuroprotective effects in MS. Pregnancy, however, is not protective in all AID. Beside beneficial effects in MS, RA, and psoriasis, other diseases such as SLE tend to flare during pregnancy. This suggests that alterations in immunity during pregnancy are not generally immunosuppressive, but selectively impaired Th1/Th17 cell-mediated immunity in a way that is beneficial in diseases such as MS. In contrast, diseases driven primarily by antibody responses are often unaffected or even exacerbated. ${ }^{[3]}$ From an evolutionary standpoint, immunological changes during pregnancy are aimed at protecting the semi-allogeneic fetus from rejection by the mother's immune system and promoting its development. ${ }^{[14,15]}$ These mechanisms involve the active suppression of cellular immunity, which may also be highly effective in suppressing CNS-autoimmunity in a mother-to-be with MS. As disease relapses often occur postpartum, it has been hypothesized that sex-steroïd hormones produced during late pregnancy could orchestrate anti-inflammatory and neuroprotective effects. ${ }^{[2,4]}$

During pregnancy, the levels of sex-steroid hormones $\mathrm{E} 2, \mathrm{E} 3$, estetrol (E4) and progesterone (P4) increase progres-

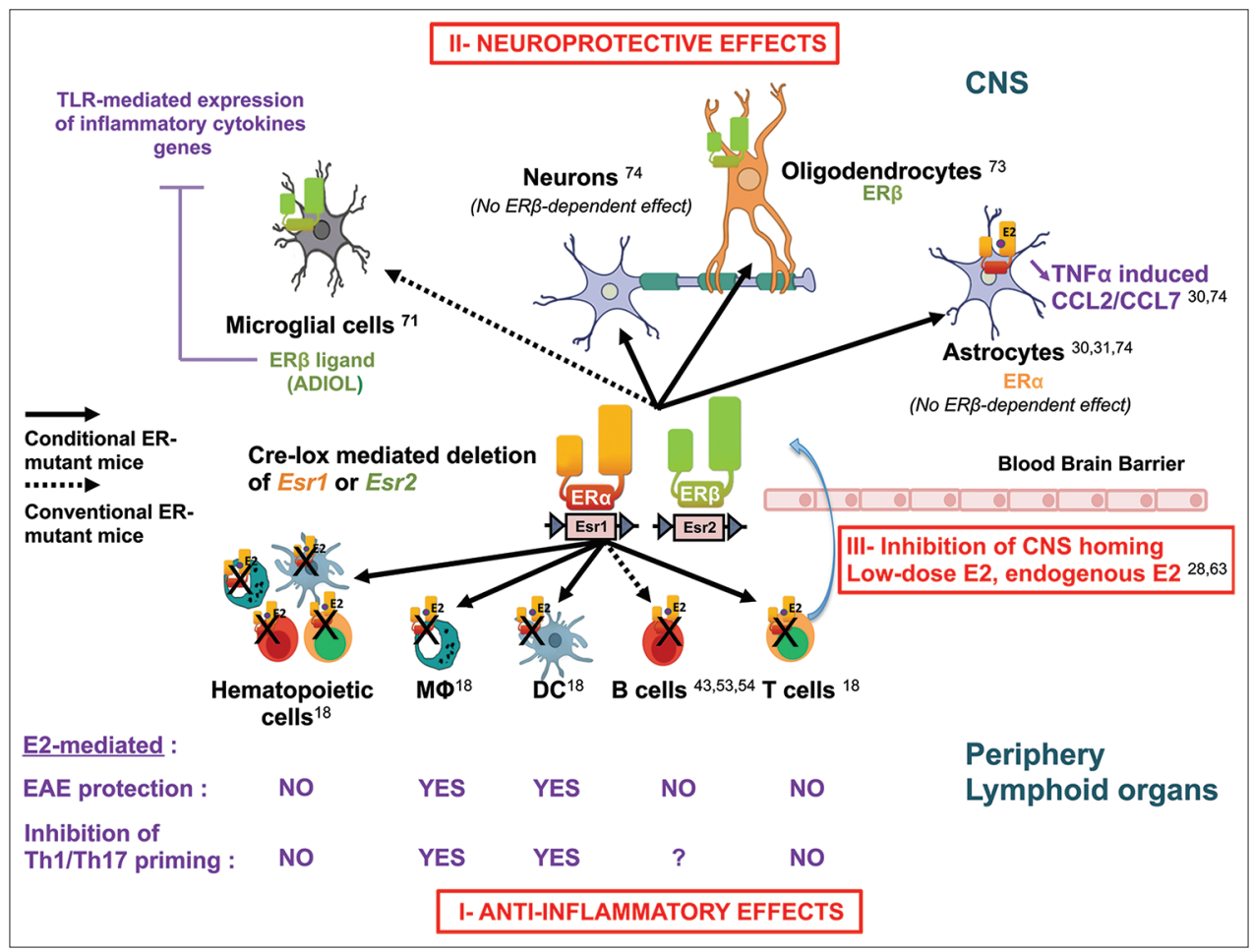

Figure 1: A simplified view of Estrogen Receptor (ER)-mediated EAE protection. Estrogens mediate experimental autoimmune encephalomyelitis (EAE) protection through distinct mechanisms targeting immune or non-immune cells. (I) ER $\alpha$-expression in T-cells is necessary and sufficient to inhibit Th1 and Th17 cells priming in lymph nodes. (II) Both ER $\alpha$ and ER $\beta$ have been implicated in the neuroprotective effects of exogenous estrogens or ER-selective agonists in EAE. (III) Low dose E2 or endogenous levels of estrogens limit EAE without inhibiting Th1/Th17 priming, through the non-hematopoietic expression of ER $\alpha$. 
sively and peak at the third trimester when disease protection is maximal. After delivery, the serum concentrations of these hormones fall making their temporal profile consistent with the protection conferred by pregnancy on MS relapse. ${ }^{[2]}$ Studies in EAE have clearly established protective effects of E2 and E3 on disease activity when administered at pregnancy doses. ${ }^{[16-18]} \mathrm{P} 4$ treatment alone showed minor effects on EAE when used alone ${ }^{[1,20]}$ and seemed to synergize with E2 to ameliorate EAE. ${ }^{[21]}$ The potential protective effects of $\mathrm{E} 4$ on EAE have to our knowledge never been studied. In MS patients, a protective effect of estrogens has been reported in a pilot clinical trial using E3. ${ }^{[6,7]}$ Large placebo-controlled clinical trials of estrogen therapy in MS are still ongoing. ${ }^{[1]}$ Estrogens are thus the best current candidate hormones to explain the protective effect of pregnancy in MS.

\section{Evidence that estrogens mediate experimental autoimmune encephalomyelitis protection through distinct mechanisms: Facts and controversies}

Pretreatment of mice, of different genetic backgrounds, with various doses of $\mathrm{E} 2$ before immunization with $\mathrm{CNS}$ autoantigens has been shown to suppress EAE development. ${ }^{[22]}$ This was associated with reduced frequency of autoantigen-specific $\mathrm{CD} 4^{+} \mathrm{T}$-cells producing interferon (IFN- $\gamma$ ) and tumor necrosis factor (TNF- $\alpha$ ), and with a shift toward Th2 cytokine synthesis, ${ }^{[23]}$ suggesting that the mechanism of estrogen-mediated protection involved a favorable alteration in cytokine production by pathogenic T-cells. Likewise, oral E3 therapy was shown to cause a significant improvement in MS patients, associated with a decreased production of TNF- $\alpha$ and an enhanced synthesis of IL- 5 and IL-10 by TCR-stimulated PBMCs. ${ }^{[7]}$ However, the Th1 to Th2 bias hypothesis was challenged by experiments showing that E2 could effectively suppress EAE in IL-4-or IL-10-knockout mice, suggesting that the E2-mediated protection did not require these two regulatory cytokines. ${ }^{[24]}$ Later, a consensus emerged, postulating that high dose estrogen-mediated EAE protection was associated with anti-inflammatory effects and strong inhibition of autoantigen-specific. The responses including both Th1, ${ }^{[17,25]}$ and Th17 cells; ${ }^{[26]}$ and that these effects are lost in mice lacking ER $\alpha .{ }^{[17,25]}$ This notion was itself subsequently challenged by experiments suggesting that the protective action of E2 was not mediated directly by E2-responsive T-cells, but rather through indirect effects on other lymphoid cells or nonlymphoid tissues. ${ }^{[27,28]}$ In an adoptive EAE model, it was shown that ER $\alpha$ expression in encephalitogenic T-cells was dispensable for E2-mediated EAE protection. ${ }^{[27]}$ Likewise, we reported that low dose E2-therapy at the time of disease induction blunted acute EAE development in the absence of ER $\alpha$ expression in hematopoietic cells. ${ }^{[28]}$ In this latter model, however, pro- tection was mainly effective during the acute phase of EAE and was not associated with immunomodulatory effects on autoantigen-specific CD4 T-cell responses in lymphoid organs in vivo. ${ }^{[28]}$ These results were altogether the first to indicate that the protective effect of E2 was not necessarily associated with inhibition of pathogenic T-cell priming, and that alternative cellular targets of $\mathrm{E} 2$ could also regulate $\mathrm{CNS}$ inflammation. Indeed, using ER $\alpha$ and $E R \beta$-specific ligands, it was subsequently reported that ER $\beta$-dependent neuroprotection could be observed in the absence of ER $\alpha$-dependent anti-inflammatory effects, ${ }^{[29]}$ though other reports suggested that $E R \alpha$ activation could also contribute to neuroprotection by decreasing the secretion of pro-inflammatory mediators in reactive astrocytes. ${ }^{[30,31]}$ This led to the hypothesis that E2 could mediate EAE protection through non overlapping mechanisms, (1) A strong anti-inflammatory effect, when E2 is given before disease induction; and (2) a neuroprotective role during the late phase of disease, involving either ER $\alpha$ or ER $\beta$ [Figure 1].

\section{Anti-inflammatory effects of estrogens in experimental autoimmune encephalomyelitis: Mechanisms and cellular targets}

The initiation of T-cell-mediated neuroinflammation requires three essential steps: (1) The activation of autoantigen-specific T-cells in the periphery, (2) their migration toward the CNS and their transendothelial trafficking across the blood-brain barrier; (3) their local reactivation in the CNS parenchyma by perivascular antigen-presenting cells (APCs) and CNS-resident microglia, leading to the initiation of an inflammatory cascade causing the recruitment of other leukocytes, particularly macrophages, which mediate myelin destruction. ${ }^{[32]}$ In the active EAE model, priming of autoantigen-specific CD4 T-cells in the secondary lymphoid tissues by dendritic cells (DC), which produce polarizing cytokines such as IL-12, IL-23, and IL-6, promotes the development of pathogenic CD4 T-cells of Th1 and Th17 phenotype. ${ }^{[32]}$ Both IFN- $\gamma$-producing Th1 and Th17 cells can induce EAE, albeit with different symptoms, depending on the preferential recruitment of either cell type to the spinal cord or the brain parenchyma. ${ }^{[33,34]}$ However, in the EAE model, it has been clearly established that the Th17-polarizing cytokine IL-23, but not IL-12, is required for disease development. ${ }^{[35,36]}$ IL-23-signaling in developing Th17 cells initiates a pathogenic program in neuroantigen-specific CD4 T-cells by stabilizing ROR $\gamma t$ expression and the production of the Th17 signature cytokines (i. e., IL-17A, IL-17F, IL-22). None of the classical Th17-associated cytokines, however, are required for disease induction, ${ }^{[37]}$ suggesting that an alternate T-cell factor is involved. Recently, it was discovered that IL-23-driven granulocyte-macrophage colony-stimulating factor (GM-CSF) secretion by pathogenic Th17 cells 
was essential for the induction of neuroinflammation in EAE. ${ }^{[38,39]}$ Indeed, T-cells lacking GM-CSF are unable to transfer disease. Upon migration to the CNS, reactivation of CD4 T-cells by perivascular DC and resident microglia, together with local production of IL-23, are required to promote the development of highly pathogenic CD4 T-cells producing Th17-cytokines and GM-CSF ${ }^{[32]}$ Although it has been hypothesized that T-cell-derived GM-CSF promotes and sustains CNS inflammation through its action on cells of hematopoietic origin, the precise mechanisms are still unknown. ${ }^{[32]}$

Estrogens could thus act at multiple levels to inhibit CNS autoimmunity, whether by down-regulating the initial pathogenic neuroantigen-specific CD4 T-cell priming in lymphoid organs or the homing of T-cells into the CNS or by limiting local re-activation of pathogenic T-cells in the CNS through direct or indirect effects on perivascular DCs or tissue-resident myeloid cells.

As mentioned above, APCs in inflammatory lymph nodes activate neuroantigen-specific naïve $\mathrm{CD} 4^{+} \mathrm{T}$-cells and provide them with cytokines (IL-12, IL-23) directing these cells to develop into pathogenic CD4+ ${ }^{+}$-cells (Th1, Th17), which expand, and traffic toward the CNS. A consistent observation in E2-mediated EAE protection is the strong anti-inflammatory effects characterized by the inhibition of autoantigen-specific $\mathrm{CD} 4^{+} \mathrm{T}$-cell responses in lymphoid organs, including both Th1, ${ }^{[17,18,23-25]}$ and Th17 cells. ${ }^{[18,26]}$ This immunosuppressive mechanism triggered by E2-treatment occurs early in the course of the MOG-specific immune response in draining lymph nodes. ${ }^{[18]}$ We showed that the proliferative response of MOG-specific $\mathrm{CD}^{+}{ }^{+} \mathrm{T}$-cells from the draining lymph nodes of E2-treated mice, and their production of IFN- $\gamma$ and IL-17 were strongly inhibited relative to nontreated mice. This inhibitory effect of E2-treatment on Th1/Th17-priming was observed from day 8 to day 12 postimmunization. ${ }^{[18]}$ More recently, using an adoptive transfer system of MOG-specific naïve 2D2 CD4 $4^{+}$T-cells, we showed that E2-treatment resulted in a strong inhibition of 2D2 lymphocyte development into pathogenic $\mathrm{CD} 4^{+} \mathrm{T}$-cells producing Th17-type cytokines such as GM-CSF (Garnier et al., in preparation). Thus, initial priming of naïve neuroantigen-specific CD4 T-cells and their subsequent development into pathogenic Th17 cells is greatly inhibited by E2-treatment, and this is likely to account in large part for the strong anti-inflammatory action of E2 and the sustained suppression of EAE observed when mice are pretreated with the hormone. ${ }^{[17,23,25]}$ Using this well-established protocol, several mechanisms have been proposed to explain this anti-inflammatory effect of E2 on EAE, such as enhanced expansion of Foxp3 ${ }^{+}$Treg cells, ${ }^{[26,40,41]}$ induction of tolerogenic $\mathrm{DC}^{[42]}$ or more recently, regulatory B cells, ${ }^{[43]}$ which may limit expansion of encephalitogenic CD4 T-cells.
Concerning Treg cells, it was initially reported that E2-mediated EAE protection was correlated with an enhanced frequency of Foxp3 $3^{+}$Treg cells in the spleen and lymph nodes, associated with greater expression of the co-inhibitory molecule PD-1 on Foxp $3^{+}$Treg cells. ${ }^{[26,40,41]}$ However, these phenotypic changes in Tregs were reported after long-term treatment with E2, around day 20 post-EAE induction. Whether such changes also occur at an earlier stage, during the priming phase in inflammatory lymph nodes, is still unclear. Despite some in vitro data indicating that "late" Tregs from E2-treated mice exhibited enhanced suppressive properties in in vitro assay, it was subsequently reported that Foxp3 ${ }^{+}$Treg cell depletion, using Foxp3-DTR deleter mice, failed to abrogate E2-mediated EAE protection. ${ }^{[44]}$ Diphtheria toxin-mediated deletion of Tregs was performed at disease onset, allowing the E2-mediated inhibition of Th1/Th17 cell priming to proceed normally in draining lymph nodes in the presence of Foxp $3^{+}$Treg cells. Although it was suggested that compensatory pathways could be implicated in E2-mediated EAE protection in the absence of Tregs, one cannot exclude that E2-sensitized Tregs are still important for the early inhibition of the priming by professional APCs of pathogenic neuroantigen-specific Th1/ Th17 cells in inflammatory lymph nodes.

Alternative cellular targets of E2-treatment have been sought, such as $\mathrm{DC}^{[42,45]}$ or B cells, ${ }^{[43]}$ which could mediate indirect inhibition of encephalitogenic T-cells. It was suggested that estrogens could mediate their anti-inflammatory action by reducing DC numbers in the secondary lymphoid organs during the priming phase ${ }^{[45]}$ or through the induction of tolerogenic DCs in vivo. ${ }^{[42]} \mathrm{E} 3$ administration in mice was found to alter substantially, the composition of splenic DC subsets, the expression of co-stimulatory and co-inhibitory molecules by these cells, and their capacity to prime MOG-specific CD4+ T lymphocytes. ${ }^{[42]}$ Despite a report showing that adoptive transfer of MOG-pulsed DCs from E3-treated mice was protective against subsequent EAE induction, ${ }^{[42]}$ the demonstration that DCs represent the primary targets responsible for the immunoregulatory effects of E3 is still lacking. In fact, using CD11c-Cre deleter mice, we recently established that ER $\alpha$-expression in peripheral DCs was dispensable for E2-mediated EAE protection. ${ }^{[18]}$ Although, we cannot exclude that the regulation of DC maturation and function could be ultimately implicated in the E2-mediated EAE protection, it is unlikely that this necessitates $\mathrm{ER} \alpha$-signaling in $\mathrm{CD} 11 \mathrm{c}^{+} \mathrm{DCs}$.

Attention has also been paid to the role of B cells in E2-mediated EAE protection. Contrasting results have been reported regarding the role of B lymphocytes in EAE pathogenesis. Studies using mice lacking B cells ( $\mu \mathrm{MT}^{/ /}$mice) have shown that while B cells are required for MOG protein-induced EAE, this population is dispensable in the 
MOG peptide-induced disease ${ }^{[46]}$ In the latter model, however, failure to resolve the clinical signs of the disease was observed. ${ }^{[47,48]}$ Disparate functions of B cells in EAE have been observed in B cell depletion experiments. Treatment with anti-CD20 antibodies before EAE induction exacerbated disease symptoms and CNS inflammation, demonstrating a regulatory function for $\mathrm{B}$ cells during the priming phase. ${ }^{[49]}$ By contrast, B cell depletion after EAE onset ameliorates disease,${ }^{[49]}$ possibly through ablation of IL-6-producing B cells. ${ }^{[50]}$ These studies identified IL-10-producing regulatory $\mathrm{B}$ cell subsets with the $\mathrm{CD} 1 \mathrm{~d}^{\text {hi }} \mathrm{CD}^{+}$phenotype, the depletion of which resulted in increased disease severity. ${ }^{[49,51]}$ Using the bone marrow chimeric system with $\mu \mathrm{Mt}$-deficient mice, it has been shown that B cells regulate CNS autoimmunity through the production of cytokines such as IL-10. ${ }^{[4]}$ More recently, it was shown that mice, where IL-35 expression was selectively deleted in B cells, lost their ability to recover from EAE. This was associated with an increased capacity to mount inflammatory T-cell responses, as well as an increased function of B cells as APCs. ${ }^{[52]}$ Altogether, these results are in favor of a regulatory role of $\mathrm{B}$ cells during the chronic phase of EAE. ${ }^{[47,52]}$

The role of B cells has been examined in E2-mediated EAE protection using B cell-deficient mice. It was shown that EAE protection by E2-treatment was partially lost in $\mu \mathrm{MT}^{/-}$mice and that passive transfer of B cells was able to ameliorate disease protection. ${ }^{[43]}$ Of note, $\mathrm{ER} \alpha^{-1-} \mathrm{B}$ cells were unable to confer enhanced protection in this adoptive transfer system, suggesting a direct action of E2 on B cells. ${ }^{[43,53]}$ In agreement with work showing that the protective action of E2 was lost in mice lacking either PD- ${ }^{[26,41]}$ or PD-L1, ${ }^{[43]}$ it was shown that PD-L1, but not PD-L2, expression on adoptively transferred B cells was required to confer some protection. ${ }^{[54]}$ However, the observation that PD-1 or PD-L1-deficient mice are refractory to E2-mediated EAE protection needs to be interpreted with caution, as these molecules are involved in the termination of T-cell responses. Indeed, PD-1 or PD-L1-deficiency have been associated with enhanced EAE development and a dramatic increase in MOG-specific Th1 and Th17 cell priming in draining lymph nodes ${ }^{[5,56]}$ Consequently, an alternative explanation could be that in PD-1KO or PD-L1KO mice, the active EAE model is less amenable to E2-mediated inhibition, as compared to wild-type mice, due to the deficient negative feedback mechanisms during T-cell priming. Nevertheless, the observation that adoptive transfer of PD-L1-deficient B cells in $\mu \mathrm{MT}^{/-}$mice failed to promote $\mathrm{E} 2 / \mathrm{ER} \alpha$-dependent $\mathrm{EAE}$ protection suggests that the PD-1/PD-L1 axis could play a role. As the recipient mice in these experiments were ER $\alpha$-proficient, however, it is still unclear whether ER $\alpha$ activation in B cells specifically is the dominant mechanism leading to EAE inhibition. ${ }^{[43,53]}$
Finally, we ignore whether this regulatory effect of B cells is linked to inhibition of pathogenic CD4 T-cell priming in inflammatory lymph nodes during EAE induction or through the promotion of the regulatory actions of B cells at later stages of disease.

\section{Anti-inflammatory effects of exogenous E2 on central nervous system autoimmunity: A critical role for $\mathrm{ER} \alpha$ in T lymphocytes}

Although T-cells were initially suspected to represent the primary target of E2, ER $\alpha$ expression in encephalitogenic T-cells was reported to be dispensable for E2 protection against EAE. ${ }^{[27,28]}$ This was shown, however, in two models designed to avoid or restrict any potential effects of E2 at the time of the induction of autoantigen-specific $\mathrm{CD}^{+} \mathrm{T}$-cell responses in vivo ${ }^{[27,28]}$ Consequently, we applied a well-established model of estrogen-mediated EAE protection to investigate whether the anti-inflammatory effect of E2 was due to a direct action of E2 on a particular immune cell population. ${ }^{[17,23,25]}$ In this model, mice are pretreated with the hormone before EAE induction, which results in long-lasting EAE protection characterized by the inhibition of pathogenic Th1/Th17 cell priming in lymphoid organs. ${ }^{[17,23,25,26]}$ By crossing ER $\alpha$-floxed mice with tissue-specific Cre-deleter mice, we generated several lines of ER $\alpha$ conditional knockout mice [Figure 1]. This included mice deficient for ER $\alpha$ in the endothelial/hematopoietic compartment (Tie2-ER $\alpha^{\mathrm{KO}}$ ), in myeloid cells $\left(\mathrm{LysM}-\mathrm{ER} \alpha^{\mathrm{KO}}\right)$, in T-cells $\left(\mathrm{CD} 4-\mathrm{ER} \alpha^{\mathrm{KO}}\right)$ or in DCs $\left(\mathrm{CD} 11 \mathrm{c}-\mathrm{ER} \alpha^{\mathrm{KO}}\right)$. Strikingly, the inhibitory effects of $\mathrm{E} 2$ treatment were lost in Tie2-ER $\alpha^{\mathrm{KO}}$ mice, demonstrating that ER $\alpha$ activation in the endothelial and/or hematopoietic compartments was critical for EAE protection by limiting MOG-specific CD4 T-cell priming and differentiation in the lymph nodes and the spleen. ${ }^{[18]}$ Using bone marrow chimera experiments, we then showed that ER $\alpha$-expression in hematopoietic cells, but not in the endothelium, was required for the anti-inflammatory effects of E2 resulting in sustained EAE protection. Based on these observations, we then sought to identify the main cellular target of E2 within the hematopoietic compartment using additional tissue-specific $\mathrm{ER} \alpha^{\mathrm{KO}}$ mouse models. The results obtained with the LysM-ER $\alpha^{\mathrm{KO}}$ and $\mathrm{CD} 11 \mathrm{c}-\mathrm{ER} \alpha^{\mathrm{KO}}$ mice showed that $\mathrm{ER} \alpha$-signaling in professional APCs, including monocyte-derived DCs and conventional DCs, were dispensable for the protective effect of $\mathrm{E} 2$ on EAE development. By contrast, using the CD4-ER $\alpha^{\mathrm{KO}}$ mouse model, we demonstrated that ER $\alpha$-signaling in $\mathrm{T}$ lymphocytes was required for sustained EAE protection. E2-treatment in these mice failed to inhibit the proliferation of MOG-specific CD4 ${ }^{+}$T-cells and their development into IFN- $\gamma$ - and IL-17-producing T-cells, by comparison with wild-type littermate controls. The residual protection observed in E2-treated CD4-ER $\alpha^{\mathrm{KO}}$ animals, however, 
suggested that additional inhibitory mechanisms were still operating. We, therefore, generated bone marrow chimeras in which $\mathrm{ER} \alpha$ was only expressed in the exogenous hematopoietic compartment. For this, irradiated Rag2 $2^{-/-} \mathrm{ER}^{-/-}$mice were reconstituted with bone marrow cells from wild-type or $\mathrm{ER}^{-/-}$mice. This model showed that ER $\alpha$ expression in the hematopoietic compartment was necessary and sufficient to mediate EAE protection. In striking contrast, when the host mice were instead reconstituted with bone marrow cells from $\mathrm{CD} 4-\mathrm{ER} \alpha^{\mathrm{KO}}$ donor mice, EAE development was unaffected by E2-treatment. EAE in these chimeras developed with similar incidence and severity as compared to untreated mice or E2-treated chimeras lacking hematopoietic ER $\alpha$. Altogether, these data firmly establish that activation of $\mathrm{ER} \alpha$ in T lymphocytes is necessary and sufficient to mediate complete EAE inhibition by E2, and, therefore, accounts for most if not all of the hematopoietic-driven protective effect of exogenous E2 on EAE. ${ }^{[18]}$

\section{Endogenous estrogens and experimental autoimmune encephalomyelitis}

Multiple sclerosis is more frequently observed in women, yet the progression of MS to more severe form of the disease is slower in females than in males, ${ }^{[57,58]}$ suggesting that sexual hormones could differentially regulate distinct developmental processes of CNS autoimmunity. Whether physiological levels of cyclical ovarian hormones in female mice have an impact of EAE has led to conflicting observations. While some studies reported that ovariectomy could worsen EAE, ${ }^{[59-61]}$ others reported no difference in clinical EAE in female mice following castration compared with sham-operated controls. ${ }^{[62]}$ We think that differences in the genetic background, the EAE induction protocol or the timing of ovariectomy may explain these apparently conflicting observations. We investigated the impact of endogenous estrogens on EAE development in female mice that were castrated before sexual maturity, at 4 weeks of age, and then assessed for active and passive EAE in adult age, at 10-12 weeks. ${ }^{[63]}$ Using both active and passive EAE models, we firmly established that endogenous estrogens exert a protective effect on EAE development and CNS inflammation through ER $\alpha$. The role of estrogen-mediated signaling in hematopoietic versus nonhematopoietic tissues was examined using ER $\alpha$-mutant mice. Altogether, our data support the conclusion that endogenous estrogens protect from EAE through ER $\alpha$-signaling in nonhematopoietic tissues by limiting the homing of inflammatory CD4+ T-cells into the CNS rather than through a direct anti-inflammatory effect on MOG-specific T-cell responses. A typical experiment is shown in Figure 2, where we assessed the kinetics of inflammatory infiltrates in the brain and spinal cord of sham-operated and ovariectomized (Ovx) mice that were adoptive recipients of MOG-specific $\mathrm{CD}^{+}{ }^{+} \mathrm{T}$-cells. Donor-derived CD4 ${ }^{+}$T-cells started to be detected in the CNS by day 5 , particularly in Ovx mice. Between day 5 and 7, higher numbers of T-cells and macrophages were recovered from the CNS of Ovx mice, as compared to sham-operated controls. Quite similar results were obtained by analyzing inflammatory infiltrates in the brain and spinal cord [Figure 2]. The enhanced recruitment of inflammatory cells in Ovx mice by day 5-7 was associated with the accelerated development of clinical EAE in this group, whereas sham controls developed EAE with onset delayed by 3-4 days relative to Ovx mice, in agreement with our earlier published data. ${ }^{[63]}$ These results are compatible with the notion that estrogen deficiency quantitatively affects transendothelial trafficking rather than the kinetics of entry of encephalitogenic $\mathrm{CD} 4^{+} \mathrm{T}$-cells into the $\mathrm{CNS}$, and in line with our previous work showing that low dose E2 could be protective in EAE, in the absence of a measurable effect on MOG-specific T-cell responses and ER $\alpha$-expression in hematopoietic cells. ${ }^{[28]}$ Endogenous estrogens may limit pathogenic T-cell recruitment into the CNS by acting on endothelial cells, which express functional ER $\alpha .{ }^{[64,65]}$ Furthermore, E2 can inhibit IL-1-dependent induction of membrane E-selectin, ICAM-1, and VCAM-1 on cultured endothelial cells. ${ }^{[66-68]}$ Interestingly, using intravital microscopy, it has been shown that ovariectomy in rats resulted in enhanced monocyte adhesion to the arterial endothelium, associated with increased adhesion molecule expression. ${ }^{[69]}$ This effect of castration was abolished by supplementation with a low dose of E2. ${ }^{[69]}$ Thus, lack of endogenous E2 seems to induce a low-grade systemic inflammation of the endothelium, which might favor transendothelial trafficking of leukocytes. This could explain the enhanced homing of encephalitogenic T-cells that we observed in Ovx female mice. Whether this is due to ER $\alpha$-signaling in the endothelial cells warrants further investigation.

This protective effect of endogenous estrogens in females does not however exclude additional mechanisms involving sex chromosome effects. Indeed, in an elegant study Voskuhl and colleagues have recently established that the CNS response to injury during EAE is differently affected between $\mathrm{XX}$ female mice and female mice bearing the XY ${ }^{\text {Sry } \Delta}$ sexual chromosomes, in which the Sry gene on Y chromosome was deleted. ${ }^{[70]}$ They showed that EAE mice with an $\mathrm{XY}^{\mathrm{Sry} \Delta}$ sex chromosome complement in the CNS, compared with $\mathrm{XX}$, demonstrated greater clinical disease severity and neurodegeneration. ${ }^{[70]}$ Altogether, these results suggest that the less progressive disease course observed in women with MS, as compared to men, might involve genetic and hormonal factors, acting independently at different stage of the disease to down-regulate inflammation into the CNS. 


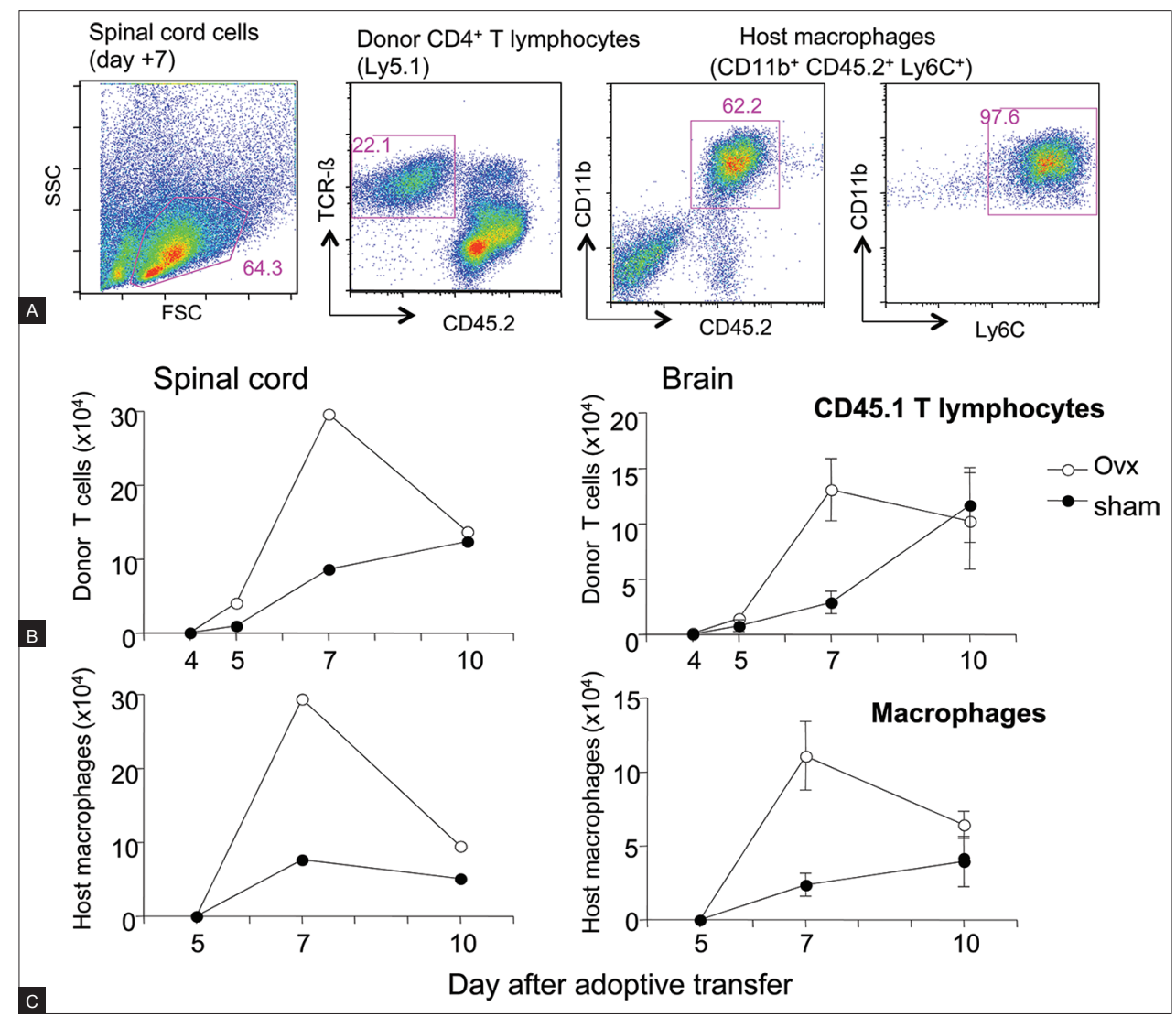

Figure 2: Castration accelerates encephalitogenic T-cell homing into the CNS in female mice. Ly5.1 MOG-specific CD4+ T-cells were injected i.v. into 10-week-old sham-operated or castrated Ly5.2 B6 female mice. At day 4, 5, 7, and 10 mice spinal cords and brains were removed. CNS-infiltrating mononuclear cells were stained with mAb specific for CD45.2, TCRß, CD4, CD11b and Ly6C (A). The absolute numbers of donor CD4+ T-cells (B) or host infiltrating macrophages (C) from individual mice (brain) or pooled spinal cord are shown.

\section{Evidence for E2 direct action on central}

\section{nervous system-resident cells implicating either estrogen receptors $\alpha$ or estrogen receptors $\beta$}

Evidence exist that estrogens, through either ER $\alpha$ or ER $\beta$, mediate anti-inflammatory or neuroprotective effects through a direct action on CNS-resident cellular targets. Two main mechanisms targeting immune or nonimmune cells have been described: (1) ER $\beta$-dependent anti-inflammatory effects on CNS-resident microglia ${ }^{[71]}$ limiting encephalitogenic CD4 T-cell recruitment into the CNS, and (2) direct neuroprotective actions on CNS-resident cells implicating either ER $\alpha$ and ER $\beta .^{[29-31]}$ Saijo et al. provided evidence that a selective modulator of ER $\beta$, ADIOL (5-androsten-3 $\beta$, 17 $\beta$-diol, a DHEA derivative), suppresses TLR-mediated inflammatory responses (IL-23, IL-6) in microglia and astrocytes. Administration of ADIOL or another ER $\beta$-ligand (Indazole-Cl) inhibited ongoing EAE in an ER $\beta$-dependent manner. E2 was shown to antagonize the anti-inflammatory activity of ADIOL, resulting in an increased transcription of inflammatory cytokine genes. ${ }^{[71]}$ Indeed, in vivo studies have shown that the innate function of microglia in response to LPS was up-regulated in the presence of endogenous and exogenous E2 in vivo. ${ }^{[72]}$ It was hypothesized that this counter-regulatory effect of E2 on microglia may account for the gender disparity in relapsing-remitting MS. ${ }^{[71]} \mathrm{Al}-$ though this work brought forth important new insights into the role of ER $\beta$ in EAE, it remains to be shown whether the pronounced effect of ER $\beta$ ligands on EAE involves a nonredundant cell-intrinsic mechanism in microglia in vivo.

Additional support for the direct neuroprotective action of ER $\beta$ ligands has been provided by others. Prior studies of the ER $\beta$ selective ligand DPN in EAE showed limited benefit, as compared to ADIOL, ${ }^{[71]}$ that was unrelated to anti-inflammatory properties. ${ }^{[29]}$ Unlike the ER $\beta$-selective ligands, indazoles or ADIOL ${ }^{[71]}$ DPN is inactive in repressing TLR-driven inflammatory gene expression in microglia, suggesting that it may act through other mechanisms in vivo. ${ }^{[71]}$ Indeed, conditional knock-out of ER $\beta$ in oligodendrocytes prevented DPN-induced improvement of clinical disease and myelination in an active EAE model. ${ }^{[73]}$ In this model, DPN-treatment had no effect on peripheral auto-antigen-specific T-cell responses and did not reduce spinal cord inflammation during EAE. Though ineffective 
on inflammation, DPN-treatment was shown to protect mice from demyelination and axonal loss, and to restore motor function. ${ }^{[29,73]}$ Moreover, using conditional ER $\beta$ knock-out mouse models, it was reported that DPN-conferred neuroprotection was not dependent on ER $\beta$-signaling in astrocytes nor in neurons, suggesting a role for oligodendrocytes as the primary targets of this ER $\beta$ ligand. ${ }^{[74]}$ Indeed, DPN was shown to act through ER $\beta$-signaling in oligodendrocytes not only to prevent demyelination, but also to promote remyelination. ${ }^{[75]}$ Thus, it has been proposed that such ER $\beta$-ligands could be used in combination with anti-inflammatory drugs in MS patients. ${ }^{[76]}$

Beside ER $\beta$-ligands, evidence also exists for ER $\alpha$-mediated neuroprotective effects. It has been shown that administration of $\mathrm{E} 2$ or ER $\alpha$-specific agonists in mice during the chronic phase of active EAE was able to inhibit the expression of inflammatory chemokines CCL2 and CCL7 by astrocytes in vivo. ${ }^{[30,74]}$ Using conditional knock-out mice, Spence et al. showed that this neuroprotective action was mediated through ER $\alpha$-signaling in astrocytes. ${ }^{[31,74]}$ Altogether, these observations suggest that differences in ER-specific ligands are not only the result of distinct pharmacological effects, but that each ligand may have different cellular targets. Interestingly, selective estrogen receptor modulators (SERMs) such as raloxifene and bazedoxifene have been recently shown to inhibit inflammatory mediator production by reactive astrocytes in vitro, which holds therapeutic promise against neuroinflammation in MS. ${ }^{[77,78]}$ Taken together, these results indicate that beside the anti-inflammatory actions of E2/ER $\alpha$ in the periphery, estrogens or ER selective agonists may also mediate neuroprotective effects through classical ER $\alpha$ or ER $\beta$ expressed by distinct cellular targets in the CNS [Figure 1]. Although neuroprotective effects of E2 or ER-specific ligands have been shown in experimental models where mice were treated after chronic EAE onset ${ }^{[30]}$ or using adoptive transfer of encephalitogenic CD4 T-cells, ${ }^{[74]}$ it is still unclear whether the neuroprotective effects of ER $\alpha$ ligands, for instance, could still be observed in the complete absence of anti-inflammatory actions due to immune cell targeting in the periphery.

\section{Genomic versus membrane-initiated signaling?}

Although ER $\alpha$ can mediate both classical genomic, as well as rapid non-genomic responses to E2, ${ }^{[79]}$ it has been suggested that an unrelated protein, the orphan $G$ protein-coupled receptor GPR30, could be responsible for the membrane-initiated nongenomic effects of E2. ${ }^{[80]}$ Studies in the EAE model have shown that administration of the GPR30 agonist, G-1, conferred protection from EAE in wild-type but not in GPR-30-deficient mice. ${ }^{[41]}$ However, a strong protective effect of E2 still persisted in GPR-30-deficient mice, suggesting that $\mathrm{ER} \alpha$ rather than
GPR-30 represented the main receptor targeted by E2. ${ }^{[41]}$ The role of GPR30 as a putative membrane ER has indeed been challenged by studies demonstrating that GPR30 does not bind $\mathrm{E} 2$ and is dispensable for the effects of estrogens on the reproductive tissues ${ }^{[81,82]}$ Moreover, GPR30 transcripts are barely detectable in lymphoid organs, ${ }^{[82]}$ and there is no evidence that hematopoietic expression of GPR30 is important to mediate EAE protection using either E2 or the specific GPR30 ligand G-1. While some works suggested that B lymphocytes could contribute to the E2-mediated inhibition of EAE through GPR30 and ER $\alpha,{ }^{[43,53]}$ it is not clear whether GPR-30-dependent mechanisms of EAE protection involve inhibition of pathogenic Th1/Th17 cell priming in lymph nodes or whether it results from other unrelated mechanisms.

Beside its classical genomic actions, E2/ER $\alpha$-signaling has been shown to modulate the activation of several kinases (MAPK, PI3K or PKC), phosphatases and the adenylyl cyclase, as well as changes in intra-cellular calcium levels. These membrane initiated steroid signaling (MISS) actions are mediated by a pool of intracellular receptors localized at the plasma membrane in caveolae or rafts. ${ }^{[83]}$ The palmitoylation of ER $\alpha$ cysteine 447 appears to be crucial for targeting the receptor to the plasma membrane through physical interaction with caveolin-1. ${ }^{[84,85]}$ Studying the in vivo role of plasma membrane-associated ER $\alpha$ in E2-mediated EAE protection is still an important issue, as membrane-initiated effects of E2 signaling have been described in immune cells such as T-cells ${ }^{[86]}$ Recently, mice carrying a point mutation of the palmitoylation site of ER $\alpha$ have been generated, which exhibit MISS loss of function ${ }^{[87]}$ Combining this model with other ER $\alpha$ mutant mice selectively lacking nuclear ER $\alpha$ actions ${ }^{[88]}$ will provide important information regarding the tissue-specific role of membrane versus nuclear actions of $\mathrm{E} 2$ on EAE protection.

\section{Conclusion}

Exogenous estrogens mediate EAE protection through distinct mechanisms targeting immune or CNS-resident cells: (i) Anti-inflammatory effects limiting encephalitogenic $\mathrm{CD} 4^{+} \mathrm{Th} 1$ and $\mathrm{Th} 17$ cell priming in lymphoid tissues and (ii) direct neuroprotective actions in CNS-resident cells. Whereas both $\mathrm{ER} \alpha$ and $\mathrm{ER} \beta$ have been implicated in the neuroprotective effects of estrogens, acting through different mechanisms and cellular targets, only ER $\alpha$ expression in hematopoietic cells, particularly T-cells, appears to be necessary and sufficient for mediate the anti-inflammatory effects of E2 on EAE. Low-dose exogenous E2 or natural endogenous $\mathrm{E} 2$ protects from $\mathrm{EAE}$, in the absence of anti-inflammatory effects (e.g. inhibition of autoantigen-specific $\mathrm{CD} 4^{+} \mathrm{T}$-cell priming). ER $\alpha$ expression in non hematopoietic tissues or radiation-resistant cells is required to mediate this 
effect. Lack of endogenous estrogens induces a low-grade systemic inflammation of the endothelium, which could explain the accelerated homing of pathogenic $\mathrm{CD}^{+} \mathrm{T}$-cells into the CNS. Although the relevant mechanisms are unknown, this could explain why the progression of MS to a more severe form of the disease is slower in females than in males. ${ }^{[57,89]}$ Altogether, these data suggest that estrogens could differentially regulate distinct developmental processes of CNS autoimmunity depending not only on the ER isotype targeted, but also on the dose and the timing of hormone administration.

The reduction in relapse rates during late pregnancy in MS patients can attain $80 \%$, a more robust protection than that provided by treatment with IFN- $\beta$, glatiramer acetate or Natalizumab. ${ }^{[1]}$ Deciphering the pathways and mechanisms underlying the protective effects of estrogens in CNS autoimmunity is thus of critical importance to optimize estrogen receptor (ER) modulation strategies for increased efficacy, while minimizing undesired effects, in an effort to mimic the beneficial effect of pregnancy in women with MS.

\section{Acknowledgments}

This work was supported by grants from the Agence Nationale de la Recherche (ANR-PHYSIO-06-010 and ANR-GENOPAT-09-008), Conseil Régional Midi-Pyrénées, the Association pour la Recherche sur la Sclérose en Plaques (ARSEP), and the Fondation pour la Recherche Médicale (équipe labellisée FRM). We thank Dr. JE Mejia for critical reading of the manuscript.

\section{REFERENCES}

1. Gold SM, Voskuhl RR. Estrogen treatment in multiple sclerosis. J Neurol Sci 2009;286:99-103.

2. Confavreux C, Hutchinson M, Hours MM, Cortinovis-Tourniaire P, Moreau T. Rate of pregnancy-related relapse in multiple sclerosis. Pregnancy in Multiple Sclerosis Group. N Engl J Med 1998;339:285-91.

3. Whitacre CC. Sex differences in autoimmune disease. Nat Immunol 2001;2:777-80.

4. Voskuhl RR, Gold SM. Sex-related factors in multiple sclerosis susceptibility and progression. Nat Rev Neurol 2012;8:255-63.

5. Nicot A. Gender and sex hormones in multiple sclerosis pathology and therapy. Front Biosci (Landmark Ed) 2009;14:4477-515.

6. Sicotte NL, Liva SM, Klutch R, Pfeiffer P, Bouvier S, Odesa S, et al. Treatment of multiple sclerosis with the pregnancy hormone estriol. Ann Neurol 2002;52:421-8.

7. Soldan SS, Alvarez Retuerto AI, Sicotte NL, Voskuhl RR. Immune modulation in multiple sclerosis patients treated with the pregnancy hormone estriol. J Immunol 2003;171:6267-74.

8. Tintoré M, Arrambide G. Early onset multiple sclerosis: The role of gender. J Neurol Sci 2009;286:31-4.
9. Maret A, Coudert JD, Garidou L, Foucras G, Gourdy P, Krust A, et al Estradiol enhances primary antigen-specific CD4 T cell responses and Th1 development in vivo. Essential role of estrogen receptor alpha expression in hematopoietic cells. Eur J Immunol 2003;33:512-21.

10. Delpy L, Douin-Echinard V, Garidou L, Bruand C, Saoudi A, Guéry JC. Estrogen enhances susceptibility to experimental autoimmune myasthenia gravis by promoting type 1-polarized immune responses. J Immunol 2005; 175:5050-7.

11. Calippe B, Douin-Echinard V, Delpy L, Laffargue M, Lélu K, Krust A, et al. 17Beta-estradiol promotes TLR4-triggered proinflammatory mediator production through direct estrogen receptor alpha signaling in macrophages in vivo. J Immunol 2010;185:1169-76.

12. Calippe B, Douin-Echinard V, Laffargue M, Laurell H, Rana-Poussine V, Pipy B, et al. Chronic estradiol administration in vivo promotes the proinflammatory response of macrophages to TLR4 activation: Involvement of the phosphatidylinositol 3-kinase pathway. J Immunol 2008;180:7980-8.

13. Seillet $\mathrm{C}$, Laffont $\mathrm{S}$, Trémollières $\mathrm{F}$, Rouquié $\mathrm{N}$, Ribot $\mathrm{C}$, Arnal JF, et al. The TLR-mediated response of plasmacytoid dendritic cells is positively regulated by estradiol in vivo through cell-intrinsic estrogen receptor a signaling. Blood 2012;119:454-64.

14. Aluvihare VR, Betz AG. The role of regulatory $\mathrm{T}$ cells in alloantigen tolerance. Immunol Rev 2006;212:330-43.

15. Erlebacher A. Mechanisms of T cell tolerance towards the allogeneic fetus. Nat Rev Immunol 2013;13:23-33.

16. Polanczyk M, Yellayi S, Zamora A, Subramanian S, Tovey M, VandenbarkAA, et al. Estrogen receptor-1 (Esr1) and -2 (Esr2) regulate the severity of clinical experimental allergic encephalomyelitis in male mice. Am J Pathol 2004;164:1915-24.

17. Liu HB, Loo KK, Palaszynski K, Ashouri J, Lubahn DB, Voskuhl RR. Estrogen receptor alpha mediates estrogen's immune protection in autoimmune disease. J Immunol 2003;171:6936-40.

18. Lélu K, Laffont S, Delpy L, Paulet PE, Périnat T, Tschanz SA, et al. Estrogen receptor a signaling in $\mathrm{T}$ lymphocytes is required for estradiol-mediated inhibition of Th1 and Th17 cell differentiation and protection against experimental autoimmune encephalomyelitis. J Immunol 2011;187:2386-93.

19. Kim S, Liva SM, Dalal MA, Verity MA, Voskuhl RR. Estriol ameliorates autoimmune demyelinating disease: Implications for multiple sclerosis. Neurology 1999;52:1230-8.

20. Yates MA, Li Y, Chlebeck P, Proctor T, Vandenbark AA, Offner H. Progesterone treatment reduces disease severity and increases IL-10 in experimental autoimmune encephalomyelitis. J Neuroimmunol 2010;220:136-9.

21. Garay L, Gonzalez Deniselle MC, Gierman L, Meyer M, Lima A, Roig P, et al. Steroid protection in the experimental autoimmune encephalomyelitis model of multiple sclerosis. Neuroimmunomodulation 2008;15:76-83.

22. Offner H. Neuroimmunoprotective effects of estrogen and derivatives in experimental autoimmune encephalomyelitis: Therapeutic implications for multiple sclerosis. J Neurosci Res 2004;78:603-24.

23. Bebo BF Jr, Fyfe-Johnson A, Adlard K, Beam AG, Vandenbark AA, Offner H. Low-dose estrogen therapy ameliorates experimental autoimmune encephalomyelitis in two different inbred mouse strains. J Immunol 2001;166:2080-9.

24. Ito A, Bebo BF Jr, Matejuk A, Zamora A, Silverman M, 
Fyfe-Johnson A, et al. Estrogen treatment down-regulates TNF-alpha production and reduces the severity of experimental autoimmune encephalomyelitis in cytokine knockout mice. J Immunol 2001;167:542-52.

25. Polanczyk M, Zamora A, Subramanian S, Matejuk A, Hess DL, Blankenhorn EP, et al. The protective effect of 17beta-estradiol on experimental autoimmune encephalomyelitis is mediated through estrogen receptor-alpha. Am J Pathol 2003;163:1599-605.

26. Wang C, Dehghani B, Li Y, Kaler LJ, Vandenbark AA, Offner H. Oestrogen modulates experimental autoimmune encephalomyelitis and interleukin-17 production via programmed death 1 . Immunology 2009;126:329-35.

27. Polanczyk MJ, Jones RE, Subramanian S, Afentoulis M, Rich C, Zakroczymski $\mathrm{M}$, et al. T lymphocytes do not directly mediate the protective effect of estrogen on experimental autoimmune encephalomyelitis. Am J Pathol 2004;165:2069-77.

28. Garidou L, Laffont S, Douin-Echinard V, Coureau C, Krust A, Chambon $\mathrm{P}$, et al. Estrogen receptor alpha signaling in inflammatory leukocytes is dispensable for 17 beta-estradiol-mediated inhibition of experimental autoimmune encephalomyelitis. J Immunol 2004;173:2435-42.

29. Tiwari-Woodruff S, Morales LB, Lee R, Voskuhl RR. Differential neuroprotective and antiinflammatory effects of estrogen receptor (ER) alpha and ERbeta ligand treatment. Proc Natl Acad Sci USA 2007;104:14813-8.

30. Giraud SN, Caron CM, Pham-Dinh D, Kitabgi P, Nicot AB. Estradiol inhibits ongoing autoimmune neuroinflammation and NFkappaB-dependent CCL2 expression in reactive astrocytes. Proc Natl Acad Sci USA 2010;107:8416-21.

31. Spence RD, Hamby ME, Umeda E, Itoh N, Du S, Wisdom AJ, et al. Neuroprotection mediated through estrogen receptor-alpha in astrocytes. Proc Natl Acad Sci USA 2011;108:8867-72.

32. Codarri L, Greter M, Becher B. Communication between pathogenic $\mathrm{T}$ cells and myeloid cells in neuroinflammatory disease. Trends Immunol 2013;34:114-9.

33. Kroenke MA, Carlson TJ, Andjelkovic AV, Segal BM. IL-12- and IL-23-modulated T cells induce distinct types of EAE based on histology, CNS chemokine profile, and response to cytokine inhibition. J Exp Med 2008;205:1535-41.

34. Stromnes IM, Cerretti LM, Liggitt D, Harris RA, Goverman JM. Differential regulation of central nervous system autoimmunity by T (H) 1 and T (H) 17 cells. Nat Med 2008;14:337-42.

35. Cua DJ, Sherlock J, Chen Y, Murphy CA, Joyce B, Seymour B, et al. Interleukin-23 rather than interleukin-12 is the critical cytokine for autoimmune inflammation of the brain. Nature 2003;421:744-8.

36. Langrish CL, Chen Y, Blumenschein WM, Mattson J, Basham B, Sedgwick JD, et al. IL-23 drives a pathogenic T cell population that induces autoimmune inflammation. J Exp Med 2005;201:233-40.

37. Haak S, Croxford AL, Kreymborg K, Heppner FL, Pouly S, Becher B, et al. IL-17A and IL-17F do not contribute vitally to autoimmune neuro-inflammation in mice. J Clin Invest 2009;119:61-9.

38. Codarri L, Gyülvészi G, Tosevski V, Hesske L, Fontana A, Magnenat L, et al. ROR $\gamma$ drives production of the cytokine GM-CSF in helper T cells, which is essential for the effector phase of autoimmune neuroinflammation. Nat Immunol 2011;12:560-7.

39. El-Behi M, Ciric B, Dai H, Yan Y, Cullimore M, Safavi F, et al. The encephalitogenicity of T (H) 17 cells is dependent on IL-1- and
IL-23-induced production of the cytokine GM-CSF. Nat Immunol 2011;12:568-75.

40. Polanczyk MJ, Carson BD, Subramanian S, Afentoulis M, Vandenbark AA, Ziegler SF, et al. Cutting edge: Estrogen drives expansion of the CD4+CD25+regulatory $\mathrm{T}$ cell compartment. J Immunol 2004;173:2227-30.

41. Wang C, Dehghani B, Li Y, Kaler LJ, Proctor T, Vandenbark AA, et al. Membrane estrogen receptor regulates experimental autoimmune encephalomyelitis through up-regulation of programmed death 1. J Immunol 2009;182:3294-303.

42. Papenfuss TL, Powell ND, McClain MA, Bedarf A, Singh A, Gienapp IE, et al. Estriol generates tolerogenic dendritic cells in vivo that protect against autoimmunity. J Immunol 2011;186:3346-55.

43. Bodhankar S, Wang C, Vandenbark AA, Offner H. Estrogen-induced protection against experimental autoimmune encephalomyelitis is abrogated in the absence of B cells. Eur J Immunol 2011;41:1165-75.

44. Subramanian S, Yates M, Vandenbark AA, Offner H. Oestrogen-mediated protection of experimental autoimmune encephalomyelitis in the absence of Foxp3+regulatory $\mathrm{T}$ cells implicates compensatory pathways including regulatory B cells. Immunology 2011;132:340-7.

45. Liu HY, Buenafe AC, Matejuk A, Ito A, Zamora A, Dwyer J, et al. Estrogen inhibition of EAE involves effects on dendritic cell function. J Neurosci Res 2002;70:238-48.

46. Lyons JA, San M, Happ MP, Cross AH. B cells are critical to induction of experimental allergic encephalomyelitis by protein but not by a short encephalitogenic peptide. Eur J Immunol 1999;29:3432-9.

47. Fillatreau S, Sweenie CH, McGeachy MJ, Gray D, Anderton SM. B cells regulate autoimmunity by provision of IL-10. Nat Immunol 2002;3:944-50.

48. Wolf SD, Dittel BN, Hardardottir F, Janeway CA Jr. Experimental autoimmune encephalomyelitis induction in genetically B cell-deficient mice. J Exp Med 1996;184:2271-8.

49. Matsushita T, Yanaba K, Bouaziz JD, Fujimoto M, Tedder TF. Regulatory B cells inhibit EAE initiation in mice while other B cells promote disease progression. J Clin Invest 2008;118:3420-30.

50. Barr TA, Shen P, Brown S, Lampropoulou V, Roch T, Lawrie S, et al. $B$ cell depletion therapy ameliorates autoimmune disease through ablation of IL-6-producing B cells. J Exp Med 2012;209:1001-10.

51. Yanaba K, Bouaziz JD, Haas KM, Poe JC, Fujimoto M, Tedder TF. A regulatory $\mathrm{B}$ cell subset with a unique $\mathrm{CD} 1 \mathrm{dhiCD} 5+$ phenotype controls $\mathrm{T}$ cell-dependent inflammatory responses. Immunity 2008;28:639-50.

52. Shen P, Roch T, Lampropoulou V, O'Connor RA, Stervbo U, Hilgenberg E, et al. IL-35-producing B cells are critical regulators of immunity during autoimmune and infectious diseases. Nature 2014;507:366-70.

53. Bodhankar S, Vandenbark AA, Offner H. Oestrogen treatment of experimental autoimmune encephalomyelitis requires 17ß-oestradiol-receptor-positive B cells that up-regulate PD-1 on CD4+Foxp3+regulatory T cells. Immunology 2012;137:282-93.

54. Bodhankar S, Galipeau D, Vandenbark AA, Offner H. PD-1 Interaction with $\mathrm{PD}-\mathrm{L} 1$ but not $\mathrm{PD}-\mathrm{L} 2$ on $\mathrm{B}$-cells mediates protective effects of estrogen against EAE. J Clin Cell Immunol 2013;4:143.

55. Salama AD, Chitnis T, Imitola J, Ansari MJ, Akiba H, Tushima F, et al. Critical role of the programmed death-1 (PD-1) pathway in 
regulation of experimental autoimmune encephalomyelitis. J Exp Med 2003;198:71-8.

56. Carter LL, Leach MW, Azoitei ML, Cui J, Pelker JW, Jussif J, et al. PD-1/PD-L1, but not PD-1/PD-L2, interactions regulate the severity of experimental autoimmune encephalomyelitis. J Neuroimmunol 2007;182:124-34.

57. Confavreux C, Vukusic S, Adeleine P. Early clinical predictors and progression of irreversible disability in multiple sclerosis: An amnesic process. Brain 2003;126 (Pt 4):770-82.

58. El-Etr M, Vukusic S, Gignoux L, Durand-Dubief F, Achiti I, Baulieu EE, et al. Steroid hormones in multiple sclerosis. J Neurol Sci 2005;233:49-54.

59. Jansson L, Olsson T, Holmdahl R. Estrogen induces a potent suppression of experimental autoimmune encephalomyelitis and collagen-induced arthritis in mice. J Neuroimmunol 1994;53:203-7.

60. Offner H, Adlard K, Zamora A, Vandenbark AA. Estrogen potentiates treatment with T-cell receptor protein of female mice with experimental encephalomyelitis. J Clin Invest 2000;105:1465-72.

61. Fillmore PD, Blankenhorn EP, Zachary JF, Teuscher C. Adult gonadal hormones selectively regulate sexually dimorphic quantitative traits observed in experimental allergic encephalomyelitis. Am J Pathol 2004; $164: 167-75$.

62. Voskuhl RR, Palaszynski K. Sex hormones in experimental autoimmune encephalomyelitis: Implications for multiple sclerosis. Neuroscientist 2001;7:258-70.

63. Lélu K, Delpy L, Robert V, Foulon E, Laffont S, Pelletier L, et al. Endogenous estrogens, through estrogen receptor a, constrain autoimmune inflammation in female mice by limiting CD4+T-cell homing into the CNS. Eur J Immunol 2010;40:3489-98.

64. Toutain CE, Filipe C, Billon A, Fontaine C, Brouchet L, Guéry JC, et al. Estrogen receptor alpha expression in both endothelium and hematopoietic cells is required for the accelerative effect of estradiol on reendothelialization. Arterioscler Thromb Vasc Biol 2009;29:1543-50

65. Billon-Galés A, Fontaine C, Douin-Echinard V, Delpy L, Berges H, Calippe B, et al. Endothelial estrogen receptor-alpha plays a crucial role in the atheroprotective action of 17beta-estradiol in low-density lipoprotein receptor-deficient mice. Circulation 2009;120:2567-76.

66. Nakai $\mathrm{K}$, Itoh $\mathrm{C}$, Hotta $\mathrm{K}$, Itoh $\mathrm{T}$, Yoshizumi M, Hiramori $\mathrm{K}$. Estradiol-17 beta regulates the induction of VCAM-1 mRNA expression by interleukin-1 beta in human umbilical vein endothelial cells. Life Sci 1994;54:PL221-7.

67. Caulin-Glaser T, Watson CA, Pardi R, Bender JR. Effects of 17beta-estradiol on cytokine-induced endothelial cell adhesion molecule expression. J Clin Invest 1996;98:36-42.

68. Simoncini T, Maffei S, Basta G, Barsacchi G, Genazzani AR, Liao JK, et al. Estrogens and glucocorticoids inhibit endothelial vascular cell adhesion molecule-1 expression by different transcriptional mechanisms. Circ Res 2000;87:19-25.

69. Abu-Taha M, Rius C, Hermenegildo C, Noguera I, Cerda-Nicolas JM, Issekutz AC, et al. Menopause and ovariectomy cause a low grade of systemic inflammation that may be prevented by chronic treatment with low doses of estrogen or losartan. J Immunol 2009; 183:1393-402.

70. Du S, Itoh N, Askarinam S, Hill H, Arnold AP, Voskuhl RR. XY sex chromosome complement, compared with XX, in the CNS confers greater neurodegeneration during experimental autoimmune encephalomyelitis. Proc Natl Acad Sci USA 2014;111:2806-11.

71. Saijo K, Collier JG, Li AC, Katzenellenbogen JA, Glass CK. An ADIOL-ERß-CtBP transrepression pathway negatively regulates microglia-mediated inflammation. Cell 2011;145:584-95.

72. Soucy G, Boivin G, Labrie F, Rivest S. Estradiol is required for a proper immune response to bacterial and viral pathogens in the female brain. J Immunol 2005;174:6391-8.

73. Khalaj AJ, Yoon J, Nakai J, Winchester Z, Moore SM, Yoo T, et al. Estrogen receptor (ER) $\beta$ expression in oligodendrocytes is required for attenuation of clinical disease by an ERß ligand. Proc Natl Acad Sci USA 2013;110:19125-30.

74. Spence RD, Wisdom AJ, Cao Y, Hill HM, Mongerson CR, Stapornkul B, et al. Estrogen mediates neuroprotection and anti-inflammatory effects during EAE through ER $\alpha$ signaling on astrocytes but not through ERß signaling on astrocytes or neurons. J Neurosci 2013;33:10924-33

75. Crawford DK, Mangiardi M, Song B, Patel R, Du S, Sofroniew MV, et al. Oestrogen receptor beta ligand: A novel treatment to enhance endogenous functional remyelination. Brain 2010;133:2999-3016.

76. Spence RD, Voskuhl RR. Neuroprotective effects of estrogens and androgens in CNS inflammation and neurodegeneration. Front Neuroendocrinol 2012;33:105-15.

77. Cerciat M, Unkila M, Garcia-Segura LM, Arevalo MA. Selective estrogen receptor modulators decrease the production of interleukin-6 and interferon-gamma-inducible protein- 10 by astrocytes exposed to inflammatory challenge in vitro. Glia 2010;58:93-102.

78. Li R, Xu W, Chen Y, Qiu W, Shu Y, Wu A, et al. Raloxifene suppresses experimental autoimmune encephalomyelitis and NF- $\mathrm{\kappa B}-$ dependent CCL20 expression in reactive astrocytes. PLoS One 2014;9:e94320.

79. Levin ER. Integration of the extranuclear and nuclear actions of estrogen. Mol Endocrinol 2005;19:1951-9.

80. Prossnitz ER, Arterburn JB, Smith HO, Oprea TI, Sklar LA, Hathaway HJ. Estrogen signaling through the transmembrane G protein-coupled receptor GPR30. Annu Rev Physiol 2008;70:165-90.

81. Otto C, Rohde-Schulz B, Schwarz G, Fuchs I, Klewer M, Brittain D, et al. G protein-coupled receptor 30 localizes to the endoplasmic reticulum and is not activated by estradiol. Endocrinology $2008 ; 149: 4846-56$

82. Otto C, Fuchs I, Kauselmann G, Kern H, Zevnik B, Andreasen P, et al. GPR30 does not mediate estrogenic responses in reproductive organs in mice. Biol Reprod 2009;80:34-41.

83. Kim KH, Bender JR. Membrane-initiated actions of estrogen on the endothelium. Mol Cell Endocrinol 2009;308:3-8.

84. Razandi M, Alton G, Pedram A, Ghonshani S, Webb P, Levin ER. Identification of a structural determinant necessary for the localization and function of estrogen receptor alpha at the plasma membrane. Mol Cell Biol 2003;23:1633-46.

85. Acconcia F, Ascenzi P, Bocedi A, Spisni E, Tomasi V, Trentalance A, et al. Palmitoylation-dependent estrogen receptor alpha membrane localization: Regulation by 17 beta-estradiol. Mol Biol Cell $2005 ; 16: 231-7$

86. Benten WP, Lieberherr M, Giese G, Wunderlich F. Estradiol binding to cell surface raises cytosolic free calcium in T cells. FEBS Lett 1998;422:349-53.

87. Adlanmerini M, Solinhac R, Abot A, Fabre A, Raymond-Letron I, Guihot AL, et al. Mutation of the palmitoylation site of estrogen 
receptor a in vivo reveals tissue-specific roles for membrane versus nuclear actions. Proc Natl Acad Sci USA 2014;111:E283-90.

88. Billon-Galés A, Krust A, Fontaine C, Abot A, Flouriot G, Toutain C, et al. Activation function 2 (AF2) of estrogen receptor-alpha is required for the atheroprotective action of estradiol but not to accelerate endothelial healing. Proc Natl Acad Sci USA 2011;108:13311-6.

89. Koch M, Kingwell E, Rieckmann P, Tremlett H; UBC MS Clinic Neurologists. The natural history of secondary progressive multiple sclerosis. J Neurol Neurosurg Psychiatry 2010;81:1039-43. 